\title{
GCU
}

Glasgow Caledonian

University

University for the Common Good

\section{Assessment of recycled glass and expanded clay in a dual media configuration for drinking water treatment}

Cescon, Anna; Jiang, Jia-Qian; Haffey, Mark ; Moore, Graeme ; Callaghan, Kevin

Published in:

Separation Science and Technology

DOI:

10.1080/01496395.2016.1209522

Publication date:

2016

Document Version

Author accepted manuscript

Link to publication in ResearchOnline

Citation for published version (Harvard):

Cescon, A, Jiang, J-Q, Haffey, M, Moore, G \& Callaghan, K 2016, 'Assessment of recycled glass and expanded clay in a dual media configuration for drinking water treatment', Separation Science and Technology, vol. 51, no. 14, pp. 2455-2464. https://doi.org/10.1080/01496395.2016.1209522

\section{General rights}

Copyright and moral rights for the publications made accessible in the public portal are retained by the authors and/or other copyright owners and it is a condition of accessing publications that users recognise and abide by the legal requirements associated with these rights.

Take down policy

If you believe that this document breaches copyright please view our takedown policy at https://edshare.gcu.ac.uk/id/eprint/5179 for details

of how to contact us. 


\title{
Assessment of Recycled Glass and Expanded Clay in a Dual Media Configuration for Drinking Water Treatment
}

\author{
Anna Cescon ${ }^{1}$, Jia-Qian Jiang ${ }^{1, *}$, Mark Haffey ${ }^{2}$, Graeme Moore ${ }^{2}$, Kevin Callaghan ${ }^{2}$ \\ 1 School of Engineering and Built Environment, Glasgow Caledonian University, Glasgow G4 \\ OBA, Scotland, United Kingdom
}

2 Scottish Water, 6 Castle Drive, Carnegie Campus, Dunfermline, Fife, KY11 8GG, Scotland, United Kingdom

\begin{abstract}
The aim of this study was to investigate the overall performance of different types of recycled glass media with the optimised coagulation conditions for drinking water treatment. Tests were performed using a laboratory-based filtration unit, with dual filter media configurations and synthetic raw water. The glass media showed comparable performance for both filtration and backwashing and avoided the breakthrough of particles in the effluent. Moreover, the promising performance of the glass media was a slow head loss development which should grant longer filtration runs, less backwashing requirement and thus possible clean water and energy savings. Finally, the optimised combination of filtration media and coagulation operations can lead to the best filtration performance.
\end{abstract}

Keywords: coagulation, filtration, recycled glass, expanded clay, dual filtration media

*Address correspondence to: Jia-Qian Jiang, School of Engineering and Built Environment, Glasgow Caledonian University, Glasgow G4 0BA, Scotland, United Kingdom . E-mail: jiaqian.jiang@gcu.ac.uk 


\section{INTRODUCTION}

More stringent standards for drinking water quality are pushing researches towards raising the treatment performance further, although some of the highest quality drinking water is produced in Scotland. Filtration is a fundamental process for drinking water treatment, being effective towards the removal of colour, turbidity and microorganisms [1]. An optimisation of filtration can lead to an increase in the effluent quality and a reduction in energy consumption, e.g. via a lower backwashing frequency. To this end, various approaches have been considered including the optimisation of the pre-treatment and the replacement of the traditional granular filter media. Among the pre-treatments, coagulation is particularly important; if ineffective, it is the main cause of failure performance during filtration [2]. Moreover coagulation is effective for the removal of both particulates and dissolved organic carbon (DOC) [3], the latter being one of the main targets for drinking water treatment in Scotland. Regardless of this, research on the influence of coagulation on filtration has been limited [4], especially with regards to the most recently developed filter media and their performance.

In the last few decades, developments in both filtration equipment and associated media were reviewed where glass media was listed as alternative media for water filtration [5]. Other alternative filter media include pumice [6] and crushed quartz [7]. For the waste glass, once it has been discarded, it cannot be used to produce new containers, as the colour of the glass required on the market is different. Recycling them for the use in water treatment represents a good solution to reduce the emission of $\mathrm{CO}_{2}$ in comparison with landfills of waste glasses. 
Moreover, processing and reuse of waste glasses as filter media need less energy and produce less $\mathrm{CO}_{2}$ emissions than that quarrying and processing of virgin sand as filter media $[8,9]$.

Research on the deployment of glass media in water filtration has so far been spread but of limited depth, mainly in applications in waste water treatment $[8,10-15]$, swimming pools water supply [16-18], on-site waste water treatment $[19,20]$ and a few cases for drinking water treatment. Manufacturers affirm recycled glass has shown improved performances in comparison to sand (with an efficiency increase up to $30 \%$ ), but this is generally calculated considering the cost savings associated with the different backwashing requirements and maintenance. For the similar removal percentages of particles, glass media can run $10-15 \%$ longer than the sand based filteres $[8,21,22]$. Composition media of glass with other materials were studied and reported [23], where $90 \mathrm{wt} \%$ of waste LCD glass was mixed with kaolinite, and mixtures of carbon, $\mathrm{Na}_{2} \mathrm{CO}_{3}, \mathrm{CaCO}_{3}$ and $\mathrm{Na}_{2} \mathrm{SO}_{4}$ as foaming agents and the $\mathrm{MgO}$ as a parting agent for 10 min of foaming calcination in the rotary kiln at $970-1000^{\circ} \mathrm{C}$, to form the spherical foamed filter media, which performed well in waste water treatment. Several additional studies have been conducted both for gravity filtration and pressure filtration, in single and dual media configurations. Rutledge et al. tested recycled glass media and anthracite as a dual media configuration against sand/anthracite [24]. Their data showed better performance of the sand than that of crushed glass in terms of particle count, with the exception of particle size of 5-7 $\mu \mathrm{m}$. An explanation of this is given by Soyer et al. [25], who indicated the different grain sizes of the media as the cause; 0.33 $\mathrm{mm}$ for sand vs. $0.59 \mathrm{~mm}$ for glass. 
Recycled glass in a single media configuration for gravity filtration was tested by Evans et al. [26]. In the study no significant differences were measured between sand and glass media with regards to residual turbidity and particle count. Similarities between the media for ripening times were recorded, but particle breakthrough occurred later for glass rather than for sand. The most notable differences were noted in the head loss development - for some of the runs with the glass based media it was $15 \%$ slower - and the backwash expansion, which was $10-20 \%$ higher for glass. After the addition of the filter aid, however, glass required longer backwashing times than sand [26]. Soyer et al. [25, 27] looked at both single and dual media configurations in two different studies. During the single media configuration experiments, a similar backwashing expansion was recorded for the two media. As experienced by Evans et al. [26], the head loss was smaller for glass, but the two configurations reached similar removal effectiveness. The same results were obtained with the dual media configurations, indicating a strong influence of the sand/glass layer on the process rather than the anthracite one [25,27]. A study by Davies et al [28] compared sand to several alternative filter media, including recycled glass. The lower efficiency of glass for turbidity removal was explained considering the smaller size and consequent smaller surface area of the glass-based material. The head loss (initial and development) was higher than the one experienced in the other trials and more similar to sand [28]. In the pilot seale trials no considerable difference was found between sand and glass for the removal. The initial head loss was lower for glass, and the development throughout the run was slower [28, 29]. The study performed by Bové et al. [30], aiming at considering the application of recycled glass for micro irrigation, reached different conclusions. Sand was found to cause a 
lower pressure drop than the glass based material (AFM), the authors ascribe the difference to the combined effect of different physical properties of the media.

When evaluating the performance of expanded clay (Filtralite) for water treatment, Davies et al. pointed out that a single media tends to show worse removal performance but slower head loss development which is due to the high porosity of the material [29]. Mitrouli et al. [31] compared anthracite and Filtralite as the top layer in a dual configurations including sand for the pretreatment of seawater. The sand/Filtralite filter showed equal or improved performance for various filtration rates. The major advantage was however still the slower head loss development [31]. A second investigation from the same authors involved the use of a configuration composed of two layers of Filtralite with different grain sizes and densities and sand/anthracite. Once again the behaviour differed in terms of head loss development [32]. A similar comparison was performed by Saltnes et al [33] for general purpose filtration and by Mikol et al [34] for roughing filters. The conclusions obtained in these studies did not differ from the previous ones; when metal based coagulants were used, the coarser grains of Filtralite were not able to reduce turbidity and residual metal sufficiently $[33,34]$.

The study presented in this paper aimed at assessing the performance of several filtration dual media configurations in view of a possible replacement of the traditional filter setup. The influence of coagulation on the media was evaluated through the use of different coagulants in combination with the various filter media configurations. 


\section{MATERIALS AND METHODS}

\section{Filtration unit}

Tests were performed in a laboratory setting with synthetic raw water.

The water was prepared with the addition of $50 \mathrm{mg} / \mathrm{L}$ of humic acid (Sigma Aldrich) and 0.5 $\mathrm{mg} / \mathrm{l}$ of kaolin to tap water. The characteristics of the solution thus obtained are summarised in Table 1.

The filtration unit employed is composed of a coagulation/sedimentation tank and a filtration column (155 cm with a $4.2 \mathrm{~cm}$ diameter). Due to the safety measures of the campus laboratory, the tests were conducted in an intermittent mode; the unit was operated for 4 hours each day. Although the data generated from this study is valuable to assess various filter media comparatively, the intermittent mode of the filtration operation is not recommended in drinking water treatment [35]. A constant flow rate of $2.3 \mathrm{~m}^{3} \mathrm{~m}^{-2} \mathrm{~h}^{-1}$ was maintained via a flow meter located at the bottom of the column. After said 4 hours the filter was stopped and operations were reprised the following day, after performing coagulation and sedimentation on a new batch of raw water. The end of the run was reached after 40 cumulative hours of operations or with the maximum head loss development allowable $(55 \mathrm{~cm})$.

The trials for backwashing were performed at a later stage; it was initially necessary to partially clog the media. This was achieved by performing coagulation (with $\mathrm{PACl}$ ) on similarly prepared model raw water and then proceeding to direct filtration, maintaining the slow mixing of the 
coagulated water at 35-40 rpm. Filtration was stopped when the head loss development reached $30 \mathrm{~cm}$. The procedure comprised the following steps for all the configurations: 20 minutes of water flow, 5 minutes of air and 20 final minutes of water. The turbidity of the backwash water was measured at the end of the final stage: additional 5-10 minutes of water flow were added if values above 13 NTU were observed. The water flow in each stage underwent a ramp up from 0 to $20 \mathrm{l} / \mathrm{h}$ over 2 minutes; a similar ramp down was performed at the end. The air flow was maintained at $17 \mathrm{l} / \mathrm{h}$ for each configuration, with a pressure close to the atmospheric one. To assess the effectiveness of the backwashing, filtration tests were performed at the end of the procedure described above: coagulated and settled model water was filtered at the same flow rate used for the main trials. Turbidity was measured every 15 minutes for 2 hours.

\section{Filter media}

The bed depth was maintained at $100 \mathrm{~cm}$ for all of the configurations, with a 1.5:1 ratio in favour of the heavier (glass/sand) material.

Sand and anthracite (Everzit, Evers) were tested as a reference. Three different glass based media - AFM (Dryden Aqua), Enviro Glasmedia (DMS Enviro), and FWS Glasmedia (Filtec) - were selected as ideal substitute of sand as the bottom layer in the configuration. The top layer of the alternative configurations was composed of Filtralite HC 0.8-1.6 (Maxit/Weber). A comparison of the effective sizes $\left(\mathrm{d}_{10}\right)$ and the uniformity coefficients (UC) of these media is shown in table

2. The parameters were determined through sieve analyses, with the exception of Filtralite and Everzit, for which they were provided by the manufacturer. The analyses were performed in accordance to the British standards (BS 1796-1:1986), in dry mode. A sample of the medium 
(100 g) was passed through a series of woven wire mesh with square openings; the sizes selected were $500 \mu \mathrm{m}, 710 \mu \mathrm{m}, 850 \mu \mathrm{m}$ and $1.18 \mathrm{~mm}$. The sieves were then shaken by hand for approximately 5 minutes before weighing.

The relationship between sizes and densities was also carefully considered for backwashing to be implemented without any disruption to the media [2].

In order to obtain a more thorough understanding of the performance, the media were analysed through scanning electron microscopy (SEM) with EVO 50 XVP (Zeiss). Several magnifications were attempted $(500,1000,2000)$, though ultimately images magnified 1000 times were chosen as the most significant, giving a perfect balance between the amount of detail and the clarity of the image.

\section{Coagulation}

Coagulation with aluminium sulphate (alum, Laboratory reagent grade, Fisher Chemicals), poly aluminium chloride (PACl, POLYGOLD PAC, Goldcrest Chemicals) or ferric sulphate (General purpose grade, Fisher Chemicals) preceded filtration and was followed by sedimentation. Effective dose and $\mathrm{pH}$ for each of the coagulants were determined through jar tests: the addition of the coagulant was followed by rapid mixing ( $250 \mathrm{rpm}$ for $1 \mathrm{~min}$ ), slow mixing ( $35 \mathrm{rpm}$ for 20 min) and sedimentation (30 min). A dose of $5 \mathrm{mg} / 1$ with $\mathrm{pH}$ between 6.2 and 6.7 was chosen for alum, while $7 \mathrm{mg} / 1$ and $\mathrm{pH} 6.5$ were deemed optimal for PACl. Ferric sulphate showed the best performance at $8 \mathrm{mg} / \mathrm{l}$ and $\mathrm{pH}$ between 5.5 and 6.The $\mathrm{pH}$ was adjusted with the addition of 
variable amounts of sodium hydroxide $(1 \mathrm{M})$ immediately after the coagulant, depending on the pH measurement.

During operations with the filtration unit the mixing regime was similarly performed, though the sedimentation time was increased to 90 minutes to avoid the blockage of the pump or the pipes.

\section{Analytical methods}

Samples collected from the raw water, the supernatant after coagulation/sedimentation and from the effluent after filtration were analysed according to the standard procedures [36]. The parameters considered for the evaluation included particle count in the range 0.9 to $140 \mu \mathrm{m}$ (Abakus ${ }^{\circledR}$ Mobil Fluid, Klotz), absorbance at 254 and 400 nm (6505 UV/vis, Jenway, and DR 3900, Hach Lange), turbidity (Turbidimeter TN-100, Eutech Instruments), pH (Cyberscan pH 11, Eutech Instruments), DOC (TOC-L CPH, Shimadzu UK) and suspended solids (performed according to standard with a $1.6 \mu \mathrm{m}$ glass microfibers membrane, MF 100 Fisherbrand). The measurements of DOC and the UV/vis absorbance were preceded by the filtration of the samples with a $0.45 \mu \mathrm{m}$ filter $\left(\mathrm{MF}^{\mathrm{TM}}\right.$ Millipore) under vacuum (FB70155 vacuum pump, Fisher Scientific). Particle counting, especially when referred to particles $\leq 2 \mu \mathrm{m}$, can be used as a more precise mean to measure the turbidity of the water when the value is low; it is also more sensitive to variations in the operations [37]. The absorbance at $400 \mathrm{~nm}$ is employed to measure colour, while the $254 \mathrm{~nm}$ wavelength allows an additional measurement for organic compounds, targeting those with higher molecular weights [38]. 
In addition, residual aluminium (Aluminium cuvette tests, 0.02-0.5 mg/l, Hach Lange) or iron (Iron cuvette tests, 0.2-6 mg/l, Hach Lange) concentrations were measured at regular intervals.

\section{RESULTS AND DISCUSSION}

\section{SEM results}

The images obtained through the SEM analysis are presented below (Fig. 1). As mentioned above, magnification and thus scale are the same in all cases.

A comparison between Figs. 1b, 1c and 1d shows clearly that the three glass media present a similar structure, with smooth surfaces and indentures along the edges, due to higher friability of the material. Sand (Fig. 1a) appears completely different, with a series of pores and a generally more irregular surface. The glass media show clearly a higher angularity in comparison to sand, which is the reason for the lower head loss development reported by other authors. The aspect of filtralite is characterised with high internal porosity (Fig. 1f), due to the production process of the material, which apparently influences the grain shape and leads to very rough grain surface. It is likely that the rough grain surface favours to the retention of deposited flocs, and therefore better filtration performance [32]. Everzit displayed in Fig. 1e shows a flatter and smoother aspect, though not to the same extent of glass. The structure appears to be formed of several planes, which might be eroded to expose the ones below. 


\section{Supernatant after coagulation/sedimentation}

The parameters measured after coagulation/sedimentation are shown in Table 3.

$\mathrm{PACl}$ shows a good performance for several contaminants in comparison to the metal salts, as previously discussed in the literature [39]. Lower efficiencies are though observed with regards to the residual suspended solids and especially for the particle count for sizes above $2 \mu \mathrm{m}$. While for the sizes $\leq 2 \mu \mathrm{m} \mathrm{PACl}$ presents a number of particles $/ \mathrm{ml}$ almost equal to half that of alum and ferric sulphate, the values are similar for the range 2-140 $\mu \mathrm{m}$, being particularly close for ferric sulphate. The higher flocculation capacity of $\mathrm{PACl}$, which grants high effectiveness for the other parameters, is likely to cause a shift towards higher values in the size distribution. Ferric sulphate allows a lower residual DOC value than Al-based coagulants, in accordance with results from previous studies $[40,41]$.

\section{Head loss development}

The head loss development measured for each of the configurations with the three coagulants selected is shown in Fig. 2. A clear trend emerges from the graphs: the use of PACl leads to the highest values for most of the configurations $(10-20 \mathrm{~cm}$ against $0-10 \mathrm{~cm})$. The stronger flocs created by this coagulant are less prone to detachment and more resistant to shear, leading to a faster clogging of the media. Filtec/Filtralite represents the exception, with a maximum value of $0.5 \mathrm{~cm}$ regardless of the coagulant. The slightly higher grain size of this specific glass based material, together with the higher porosity of Filtralite explains the result. For AFM/Filtralite and 
sand/Everzit a clear difference can be found even between pre-treatment with alum and ferric sulphate: the values are almost doubled for the latter.

Among the configurations sand/Everzit achieves the highest final values for each of the coagulants, similarly to what reported in all previous studies; the lower angularity of sand [22], compared to that of the glass media, leads to a higher head loss development, as mentioned in the SEM section.

For several configurations, the head loss development shows some peaks and drops throughout the run. This phenomenon might be caused by changes in the flow rate due to the intermittency of the operations for this study which could lead to a redistribution of particles within the filter column and thus changes in the raw water quality [34].

\section{Particle counts}

As mentioned above, particle counting is more reliable when the turbidity values are low; in this case, for the filtrate treated with PACl they never exceed $0.2 \mathrm{NTU}$ (not shown). A similar effectiveness can be observed in the results shown in Fig. 3, residual number of $\leq 2 \mu \mathrm{m}$ particles: after a brief ripening, the number is below 2000 for all the configurations when the raw water is treated with PACl. Ferric sulphate, showing values mostly above 2000 particles/ml with the exception of AFM/Filtralite, presents the worse performance in terms of residual number of particles. The configurations containing Filtralite generally show higher initial values, which might indicate the need for a longer ripening time, though they achieve good performances during the rest of the run. In terms of configurations, it is possible to see that for each of the 
coagulants, there is at least one alternative configuration outperforming sand/Everzit: a suitable alternative could be selected depending on the pre-treatment adopted by the plant.

The differences among coagulants and configurations are less conspicuous when the residual number of 2-140 $\mu \mathrm{m}$ particles is considered (Fig. 4). The alternative configurations show once again the initial ripening, though more stable values are reached towards the middle of the run ( $\sim 10-40$ particles/ml). A breakthrough towards the end is visible for the configurations across different coagulants; for the range 2-140 $\mu \mathrm{m}$ not only sand/Everzit but also Enviro/Filtralite and Filtec/Filtralite present higher values at the end of the run (40-90 particles $/ \mathrm{mL})$. In particular sand/Everzit presents breakthrough regardless of the coagulant used, while the other two configurations show higher effectiveness with aluminium based compounds. AFM/Filtralite, though being the most effective when $\mathrm{PACl}$ and ferric sulphate are used, has an increasing trend in the second half of the run with alum.

\section{DOC}

The results for residual DOC after filtration are shown in Fig. 5. A slight increasing trend towards the end of the run (final values $\sim 1.5-2 \mathrm{mg} / \mathrm{L}$ ) can be observed for some of the configurations, both with alum and ferric sulphate. Configurations containing glass-based media show efficiency similar to that of sand/Everzit; nevertheless, it has to be remembered that coagulation has been recognised as the BAT, and filtration has only a limited effect on the parameter. 
With alum as the coagulant, Filtec/Filtralite and AFM/Filtralite seem to grant the best and most consistent residual values, though some peaks are still present during the run and the latter shows an increase in the second half of the run $(>1.5 \mathrm{mg} / \mathrm{l})$. For the other two coagulants Enviro/Filtralite appears to be more effective; when $\mathrm{PACl}$ is used the performance is similar to that of sand/Everzit. The peaks appearing towards the middle of the run for the latter can likely be ascribed to analytical error.

\section{Backwashing}

The dual media configurations were backwashed according to the procedure described previously. Two backwashing cycles were performed in order to obtain reliable results; table 4 and Fig. 6 show the results for the second cycle.

Filtec/Filtralite among the configurations required the longest interval of time to reach the established head loss, and shows one of the lowest final effluent turbidity values. The need for a longer final water wash is likely due to the dislodgment of a bubble of air trapped within the bed, which freed additional contaminants temporarily increasing the waste water turbidity. The procedure was effective for all of the configurations, though mixing of the media at the interface was observed in variable quantity; a fluidised water wash could help with a complete separation of the materials. The alternative media took over 15 minutes to get below the $0.3 \mathrm{NTU}$ threshold recommended in the literature [2]; a similar ripening time was also shown previously in Figs. 2 and 3 for the particle count. Nevertheless, all of the configurations reached 0.01 NTU within 30 minutes from the start of filtration. The high turbidity values registered after the filter has been 
put back in service could be easily avoided in an industrial context with a filter-to-waste approach.

\section{CONCLUSIONS}

Conclusions emerging from this study were:

First, the alternative glass media configurations granted similar performance in relation to that of sand/anthracite in terms of the organic content removal and the residual numbers of particles. However, a slower head loss development with glass media configurations was observed; final head loss values of them were $50 \%$ lower than those obtained by sand/anthracite. This, combined with the less particle breakthrough witnessed for these configurations, could lead to a promising application of glass media in the water industry.

Secondly, a long filtration run would lead to a lower frequency of backwashing, in turn leading to the reductions in energy and backwashing water consumption. In terms of backwashing, the glass media configurations behaved similarly to sand/Everzit, with slightly longer ripening times which could be resolved when applied to a large scale trial.

Finally, the effectiveness of the chosen coagulation conditions towards filtration performance has been confirmed, and the need for a tailored optimisation for each filter media configuration has been shown. In view of a thorough improvement of the filtration process it is thus recommended to carefully evaluate the performance of the media with several coagulants to find the optimised combination that allows for the best treatment results. 


\section{ACKNOWLEDGEMENTS}

The authors are grateful to the Scottish Water who sponsored the project, and to the GCU Research Committee who offered the research studentship to Anna Cescon. The views in the paper do not necessarily represent those of the company.

\section{REFERENCES}

Cheremisinoff, N. P. (2002) Handbook of water and wastewater treatment technologies, Butterworth-Heinemann.

Hess, A.F.; Chipps, M.J.; Rachwal, A.J.; Logsdon, G.S. (2002) Filter maintenance and operations guidance manual; AWWA Research Foundation and American Water Works Association: Denver, United States.

Jiang, J.-Q. (2015) The role of coagulation in water treatment. Current Opinion in Chem. Eng., 8: $36-44$.

Gregory, D.; Carlson, K. (2003) Relationship of pH and floc formation kinetics to granular media filtration performance. Environ. Sci. Technol., 37(7): 1398-1403.

Sutherland, K. (2013) 50th Anniversary: Half a century of developments in filtration - Part 2. Filtration \& Sep., 50 (2): 16-19.

Farizoglu, B.; Nuhoglu, A.; Yildiz, E.; Keskinler, B. (2003) The performance of pumice as a filter bed material under rapid filtration conditions. Filtration \& Sep., 40(3): 41-47. 
Suthaker, S.; Smith, D.W.; Stanley, S.J. (1995) Evaluation of filter media for upgrading existing filter performance. Environ. Technol., 16(7): 625-643.

Water Development Services Report (2005) Full Scale Operational Trials Involving The Use of Recycled Glass in Selected Markets, The Waste and Resource Action Programme (WRAP), Banbury.

Enviros (2003). Report. Glass Recycling - Life Cycle Carbon Dioxide Emissions. A life Cycle Analysis, Enviros Consulting Ltd., Manchester.

Dryden Aqua Ltd (2004). Report. Tertiary Treatment of Sewage Effluent Using Recycled Glass, The Waste and Resource Action Programme (WRAP), Banbury.

Elliott, R.W. (2001) Evaluation of the use of crushed recycled glass as a filter medium: Part 1. Water Eng. Management, 148(7): 13-18.

Elliott, R.W. (2001) Evaluation of the use of crushed recycled glass as a filter medium: Part 2. Water Eng. Management,, 148(8): 17-20.

Horan, N.J.; Lowe, M. (2007) Full-scale trials of recycled glass as tertiary filter medium for wastewater treatment. Water Res., 41(1): 253-259.

Lavender, P. (2008) Filter media: Treating chemical wastewaters. Filtration \& Sep., 45(4): 1618.

Aqua Enviro (2006). Report. Full Scale Trials of Recycled Glass as Tertiary Filter Media for Wastewater Treatment, The Waste and Resource Action Programme (WRAP), Banbury. 
Hayes, C.R.; Croll, B.T.; Wright, C.; Rowlands, D.; Anex, C.; Henley, H. (2009) Removal of Cryptosporidium oocysts by filtration in the treatment of swimming pool waters, in Swimming Pool \& Spa International Conference Proceedings, London.

Korkosz, Al.; Ptaszynska, A.; Hanel, A.; Niewiadomski, M.; Hupka, J. (2012) Cullet as filter medium for swimming pool water treatment. Physicochemical Problems of Mineral Processing, 48(1): 295-301.

Aquatic Commercial Industries (1998). Report. Evaluation of Recycled Crushed Glass Sand Media for High-Rate Sand Filtration, CWC, Seattle.

Gill, L.W.; Veale, P.L.; Murray, M. (2011) Recycled glass compared to sand as a media in polishing filters for on-site wastewater treatment. Water Practice \& Technol., 6(3) doi:10.2166/wpt.2011.058.

Aqua Test Inc. and Stuth Co. Inc. (1996). Report. Crushed glass as a filter medium for the on-site treatment of wastewater, CWC, Seattle.

Dryden Aqua Ltd \& Entec UK Ltd (2004). Report. Project to examine the use of recycled glass as filtration media in the treatment of drinking water and wastewater. The Waste and Resource Action Programme (WRAP), Banbury.

Dryden Aqua (n.d.) AFM - Technical Data Sheet. Dryden Aqua Ltd., Edinburgh.

Lee, C.-T. (2014) Preparation of spherical foamed body with function of media for waste water treatment by using waste LCD glass. J. Ind. Eng. Chem., 20(5): 3089-3095. 
Rutledge, S.O.; Gagnon, G.A. (2002) Comparing crushed recycled glass to silica sand for dual media filtration. J. Environ. Eng. Sci., 1(5): 349-358.

Soyer, E.; Akgiray, O.; Eldem, N.O.; Saatci, A.M. (2010) Crushed recycled glass as a filter medium and comparison with silica sand. Clean - Soil, Air, Water, 38(10): 927-935.

Evans, G.; Dennis, P.; Cousins, M.; Campbell, R. (2002) Use of recycled crushed glass as a filtration medium in municipal potable water treatment plants. Water Sci. Technol.: Water Supply, 2(5-6): 9-16.

Soyer, E.; Akgiray, O.; Eldem, N.O.; Saatci, A.M. (2013) On the use of crushed recycled glass instead of silica sand in dual-media filters. Clean - Soil, Air, Water, 41(4): 325-332.

Davies, P. (2011). PhD thesis. Alternative filter media in rapid gravity. Loughborough University, Loughborough.

Davies, P.; Wheatley, A. D. (2012) Pilot plant study of alternative filter media for rapid gravity filtration. Water Sci. Technol., 66(12): 2779-2784.

Bové, J., Arbat, G., Duran-Ros, M., Pujol, T. (2015) Pressure drop across sand and recycled glass media used in micro irrigation filters. Biosystems Eng., 137: 55-63.

Mitrouli, S.T.; Yiantsios, S.G.; Karabelas, A.J. (2008) Pretreatment for desalination of seawater from an open intake by dual-media filtration: Pilot testing and comparison of two different media. Desalination, 222(1-3): 24-37.

Mitrouli, S.T.; Karabelas, A.J.; Yiantsios, S.G.; Kjolseth, P.A. (2009) New granular materials for dual-media filtration of seawater: Pilot testing. Sep. Purif. Technol., 65: 147-155. 
Saltnes, T.; Elkebrokk, B.; Odegaard, H. (2002) Contact filtration of humic waters: performance of an expanded clay aggregate filter (Filtralite) compared to a dual anthracite/sand filter. Water Sci. Technol.: Water Supply, 2(5-6): 17-23.

Mikol, A.; Fitzpatrick, C.S.B.; Chipps, M.J.; Steele, M.E.J.; Bayley, R.G.W. (2007) Novel dual media combination for drinking water treatment. Water Sci. Technol.: Water Supply, 7(5-6): $131-139$.

AWWA (2011) Granular Bed and Precoat Filtration, Chapter 10, in: Water Quality and Treatment: A Handbook on Drinking Water, 6th ed.; American Water Works Association, McGraw-Hill, New York.

Clesceri, L.; Greenberg, A.; Eaton, A. (2005) Standard methods for the examination of water and waste water, 21st ed.; American Public Health Association: Washington DC.

Hargesheimer, E.E.; McTigue, N.E.; Mielke, J.L.; Yee, P.; Elford, T. (1998) Tracking filter performance with particle counting. Amer. Water Works Assoc. J., 90(12): 32-41.

Matilainen, A.; Vepsäläinen, M.; Sillanpää, M. (2010) Natural organic matter removal by coagulation during drinking water treatment: a review. Advances in Colloid and Interface Sci., 159(2): 189-197.

Jiang, J-Q. (2001) Development of coagulation theory and pre-polymerized coagulants for water treatment. Sep. Purif. Reviews, 30(1): 127-141.

Bell-Ajy, K.; Abbaszadegan, M.; Ibrahim, E.; Verges, D.; LeChevallier, M. (2000) Conventional and optimized coagulation for NOM removal. Amer. Water Works Assoc. J., 92: 44-58. 
Bryant, R.; Sadar, M.; Pernitsky, D.J. (2011) Online Sensors for Monitoring and Controlling Coagulation and Filtration, in Operational Control of Coagulation and Filtration Processes Manual of Water Supply Practices, M37, 3rd ed.; American Water Works Association (AWWA). 
Figure 1. SEM images: a) clean sand, b) clean AFM, c) clean Enviro Glasmedia, d) clean FWS Glasmedia (Filtec), e) clean Everzit, f) clean Filtralite (HC 0.8-1.6)

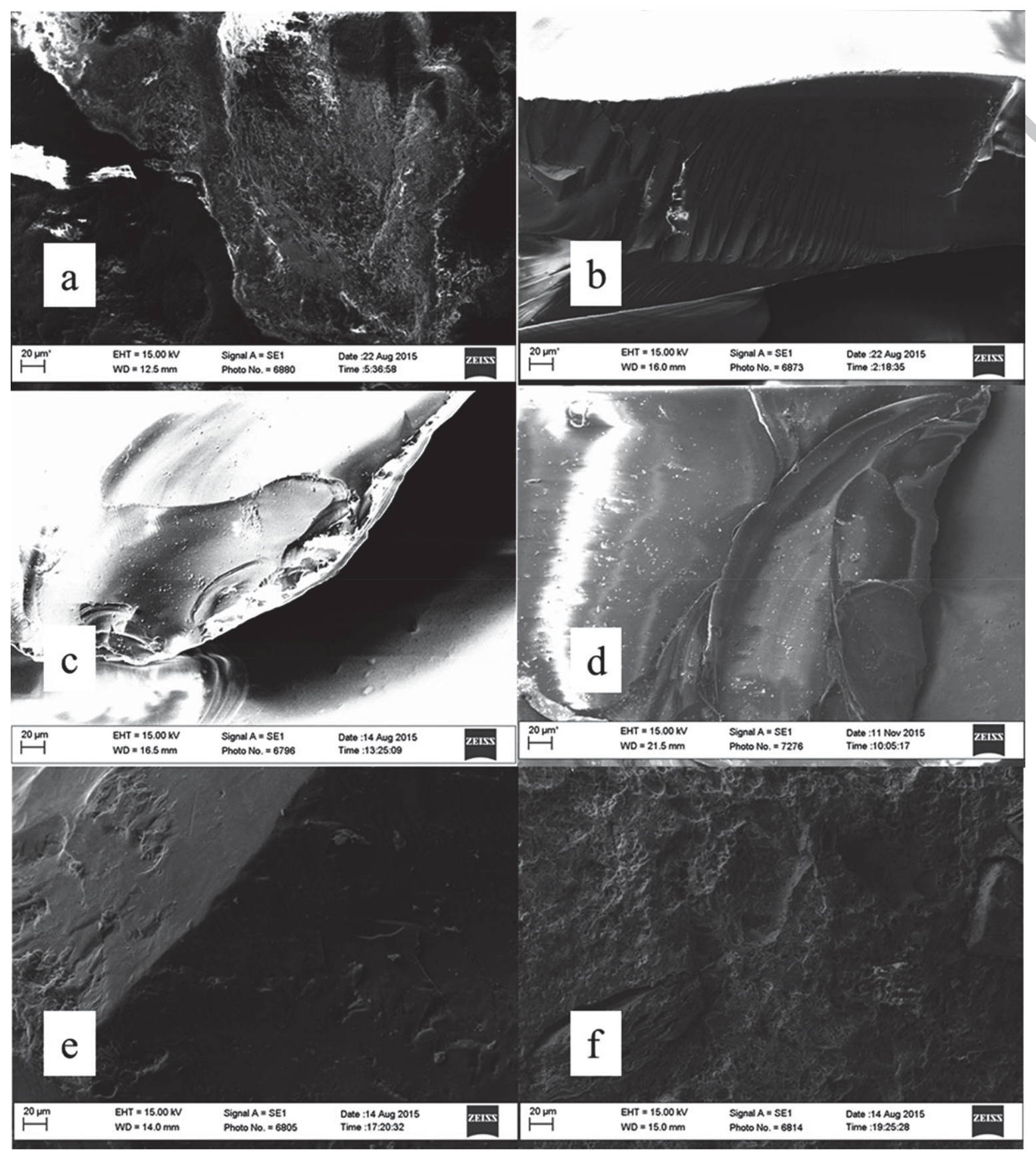


Figure 2. Head loss development for the entire run with a) alum, b) PACl, c) ferric sulphate
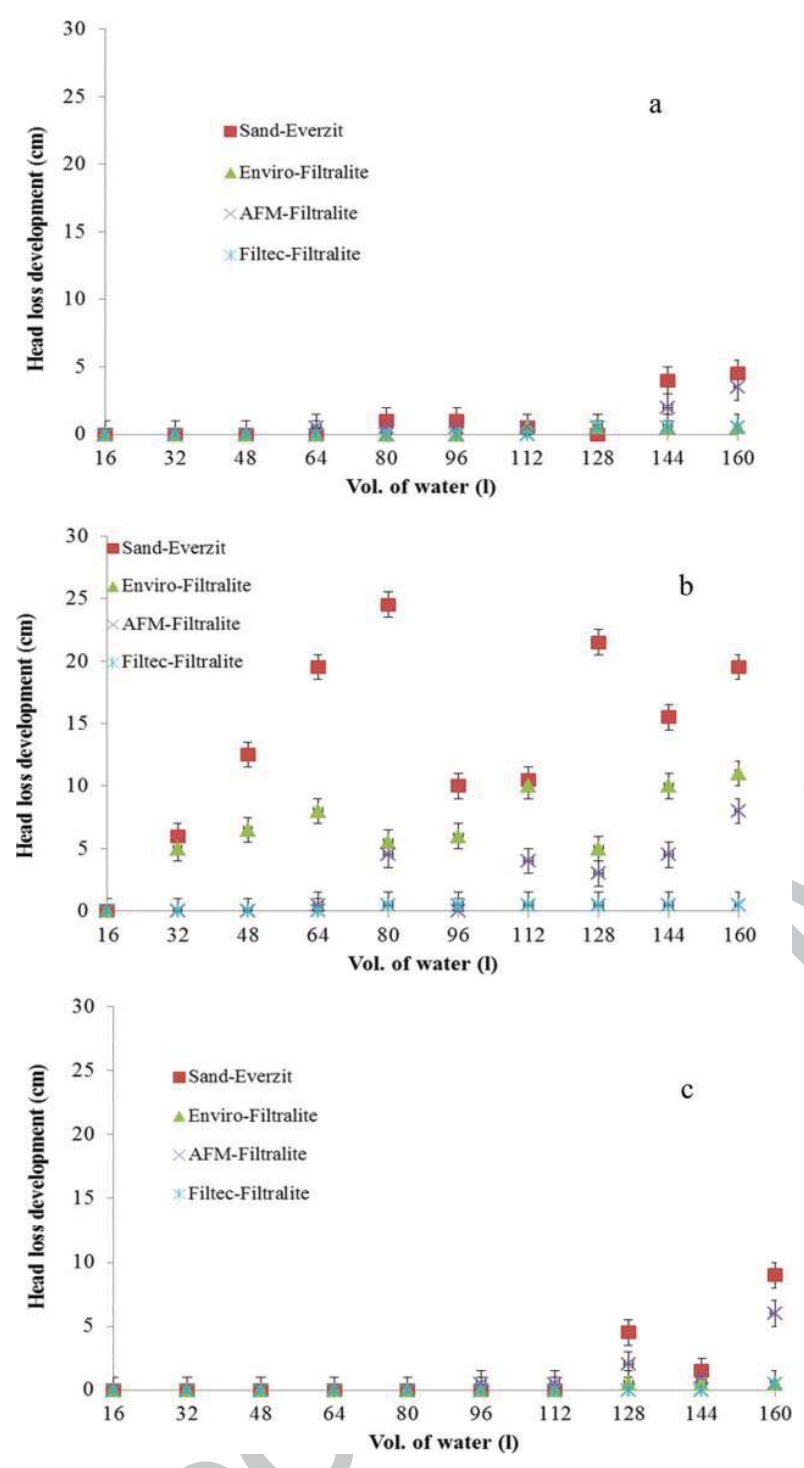
Figure 3. Residual number of $\leq 2 \mu \mathrm{m}$ particles per ml with a) alum, b) $\mathrm{PACl}$, c) ferric sulphate
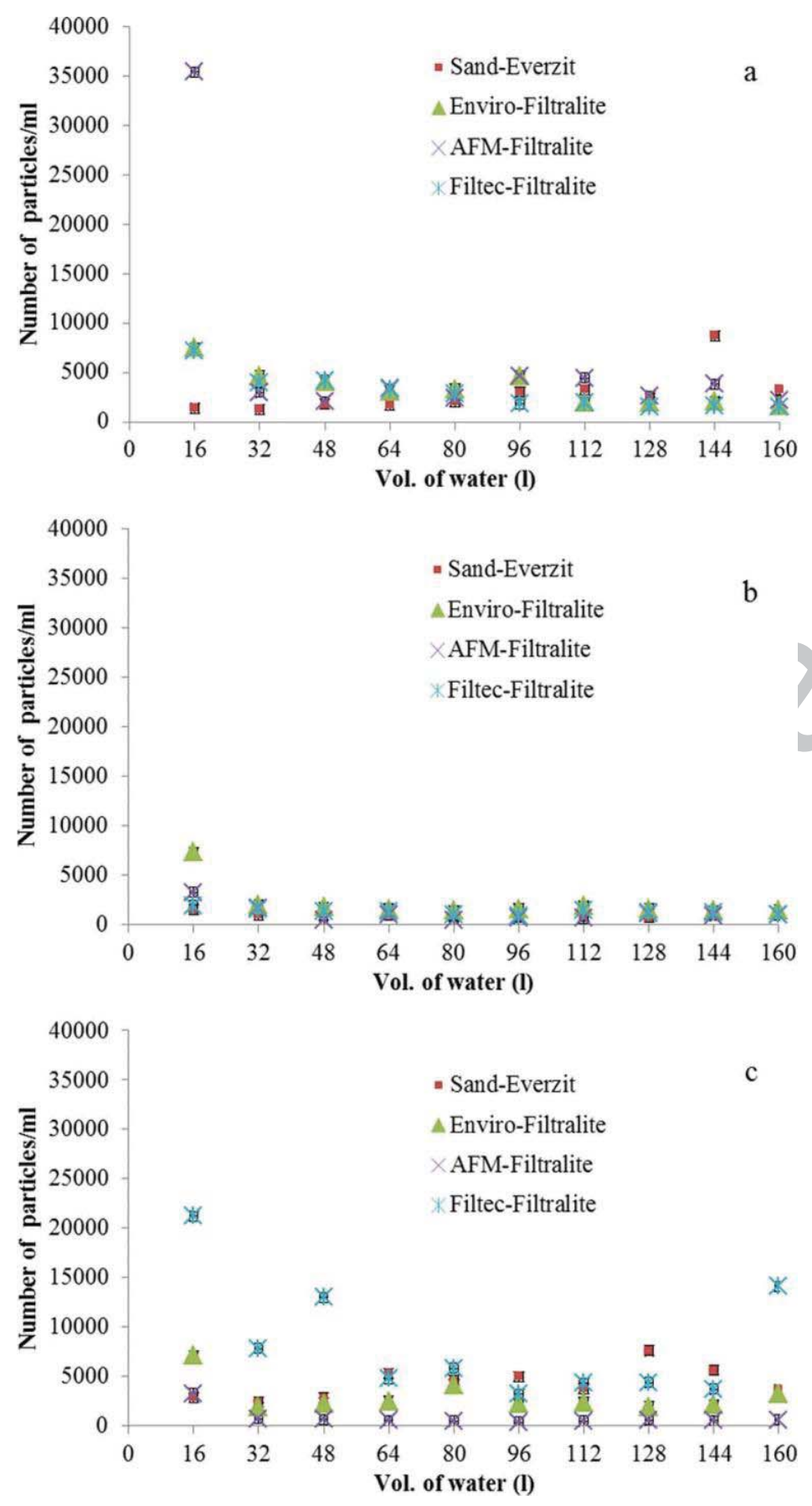
Figure 4. Residual number of 2-140 $\mu \mathrm{m}$ particles per $\mathrm{ml}$ with a) alum, b) $\mathrm{PACl}, \mathrm{c})$ ferric sulphate
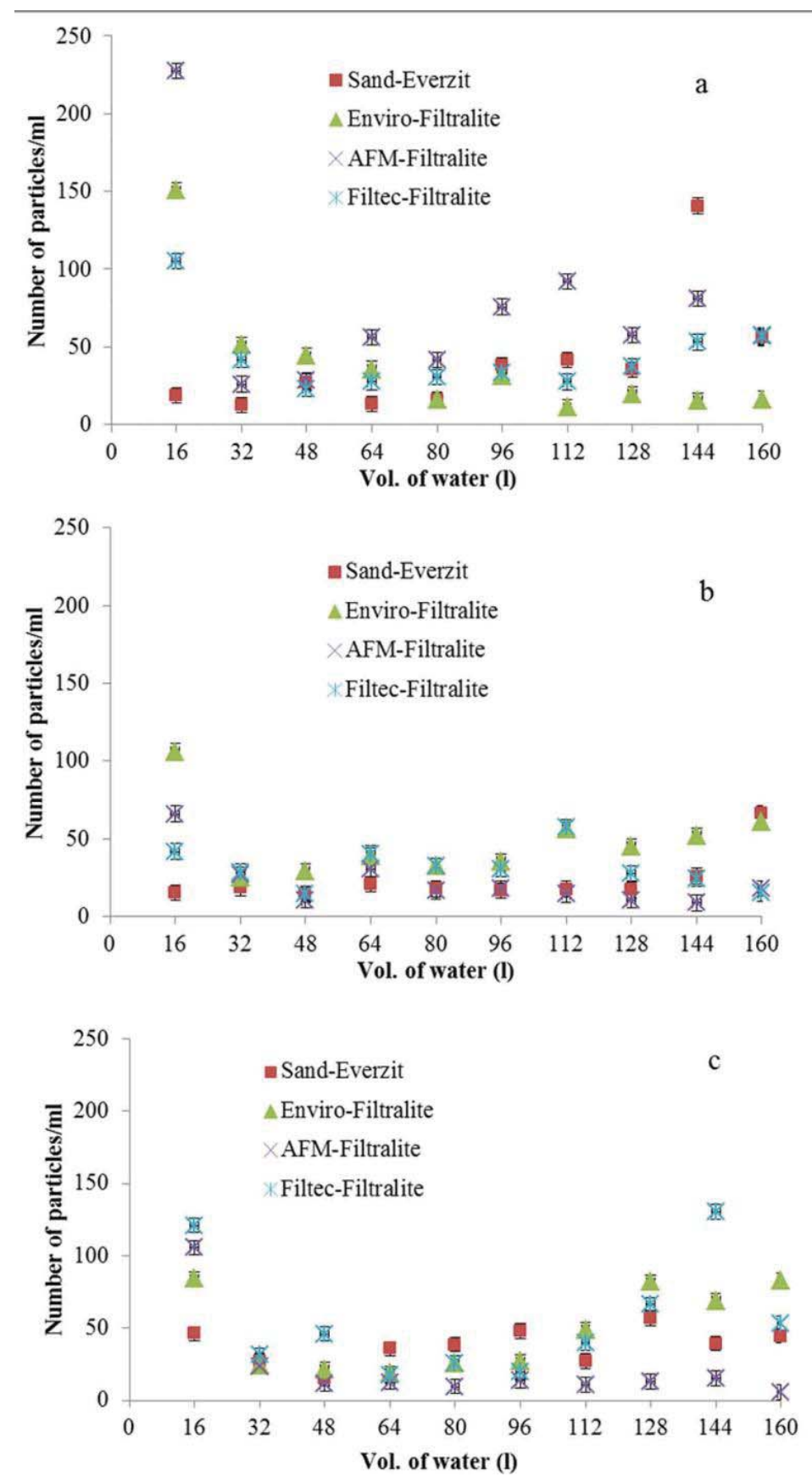
Figure 5. Residual DOC during the entire run with a) alum, b) $\mathrm{PACl}$, c) ferric sulphate
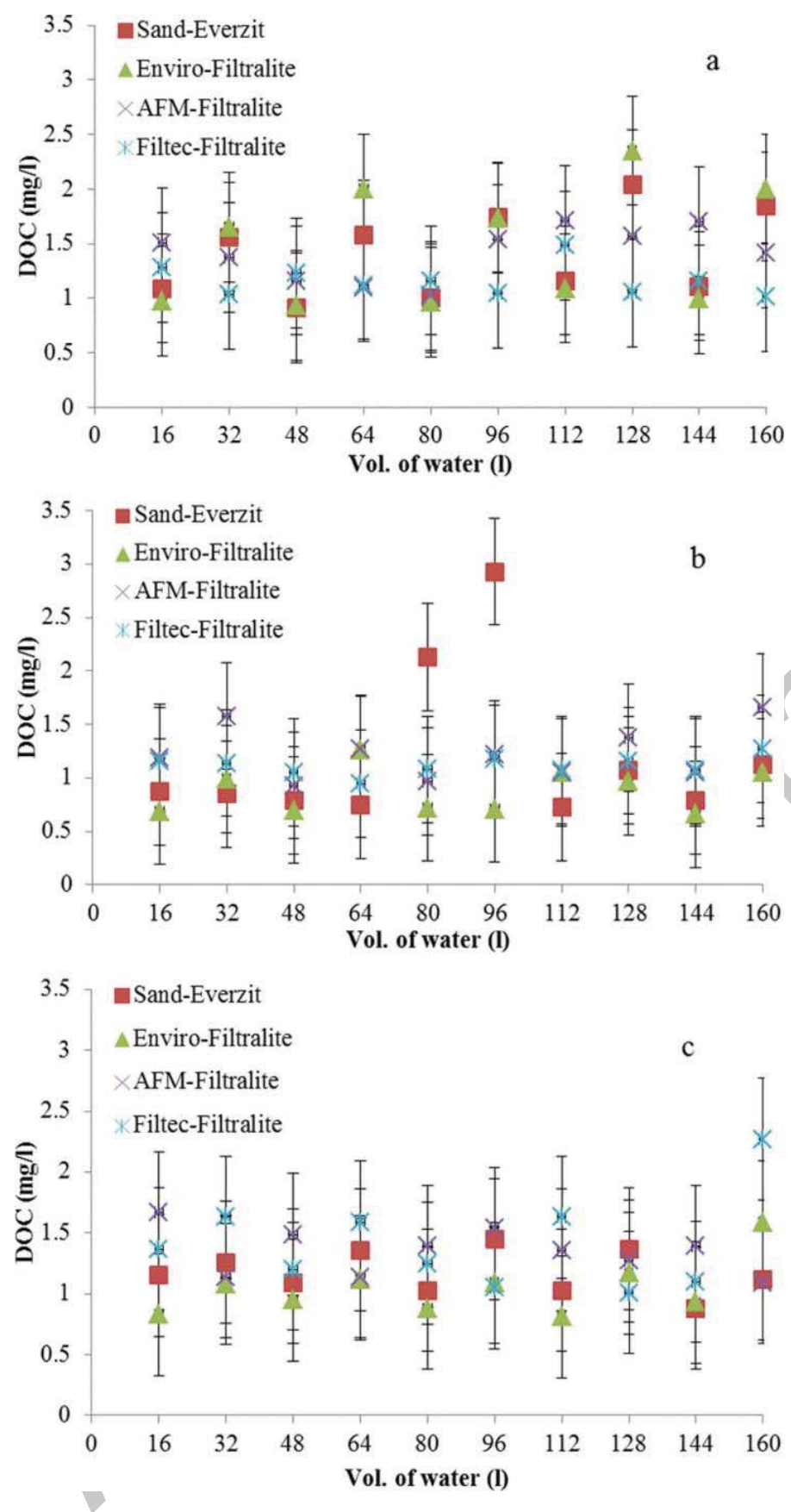
Figure 6. Turbidity in the effluent for the filtration trials performed after backwashing.

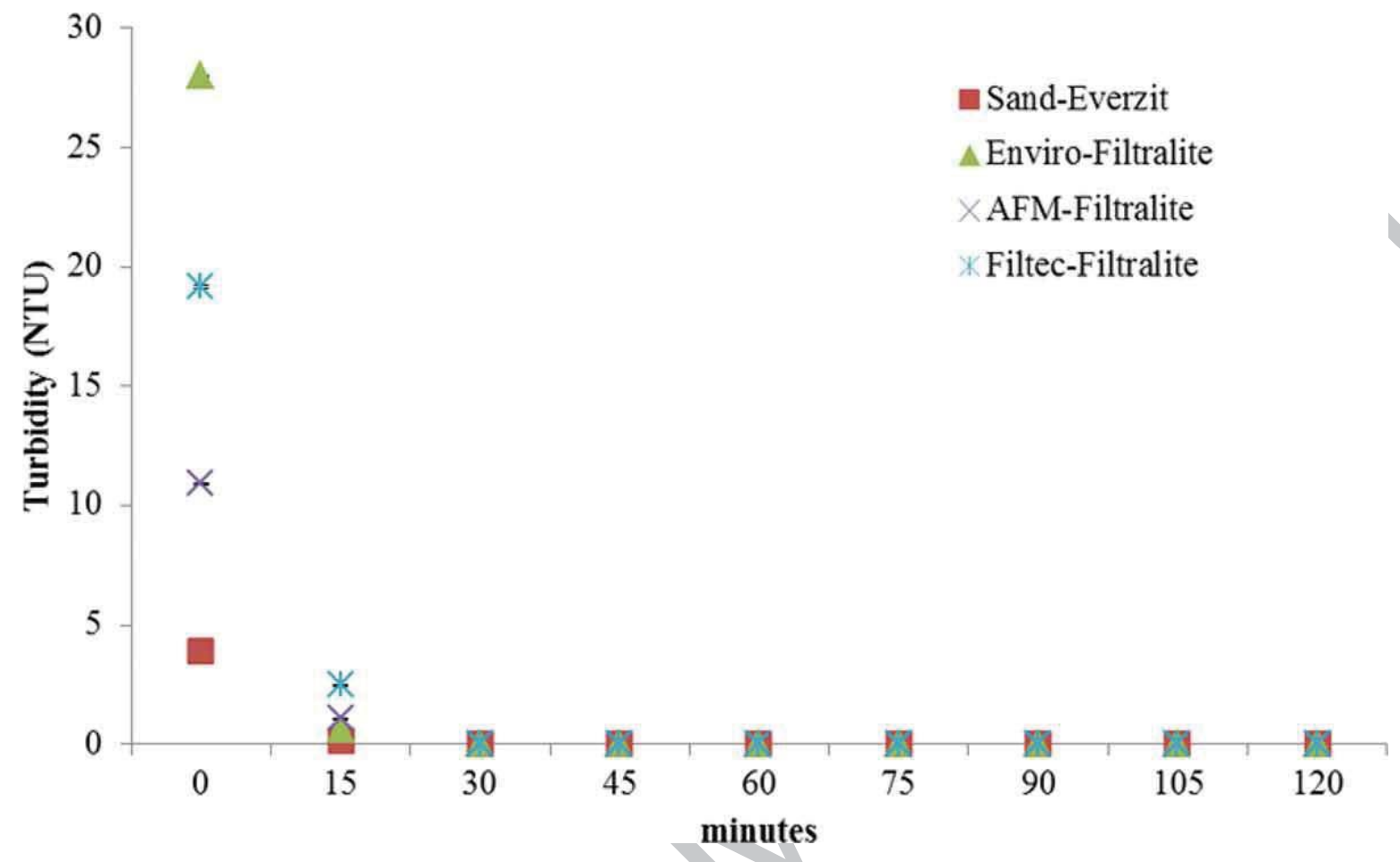


Table 1. Model raw water quality

\begin{tabular}{|c|c|c|}
\hline Parameter & Unit & Mean $( \pm \mathrm{SD})$ \\
\hline $\mathrm{pH}$ & - & $6.96( \pm 0.2)$ \\
\hline Vis-Abs & $\mathrm{m}^{-1}$ & $11.8( \pm 1.2$ \\
\hline UV-Abs & $\mathrm{m}^{-1}$ & $23.3( \pm 3.8)$ \\
\hline Turbidity & NTU & $40.9( \pm 8.9)$ \\
\hline DOC & $\mathrm{mg} / \mathrm{l}$ & $5.93( \pm 0.97)$ \\
\hline Suspended solids & & $33.5( \pm 2.1)$ \\
\hline Particle count $(\leq 2 \mu \mathrm{m})$ & particles $/ \mathrm{ml}$ & 445085 \\
\hline Particle count $(2-140 \mu \mathrm{m})$ & particles $/ \mathrm{ml}$ & 74632 \\
\hline
\end{tabular}


Table 2. Effective size and uniformity coefficient the media

\begin{tabular}{|l|l|l|}
\hline & $\mathrm{d}_{10}(\mathrm{~mm})$ & $\mathrm{UC}$ \\
\hline Sand & 0.53 & 1.38 \\
\hline AFM & 0.54 & 1.4 \\
\hline Enviro Glasmedia & 0.51 & 1.5 \\
\hline Filtec & 0.6 & 1.37 \\
\hline Filtralite & 0.9 & $<1.5$ \\
\hline Everzit & 0.9 & $<1.5$ \\
\hline
\end{tabular}


Table 3. Supernatant after coagulation/sedimentation

\begin{tabular}{|c|c|c|c|c|}
\hline Parameter & Unit & Alum & $\mathrm{PACl}$ & Ferric \\
\hline Vis-Abs & $1 / \mathrm{m}$ & $0.4( \pm 0.3)$ & $0.4( \pm 0.4)$ & $0.7( \pm 0.3)$ \\
\hline UV-Abs & $1 / \mathrm{m}$ & $1.1( \pm 0.7)$ & $0.9( \pm 0.3)$ & $1.4( \pm 0.4)$ \\
\hline Turbidity & NTU & $6.2( \pm 1.17)$ & $2.71( \pm 0.76)$ & $5.93( \pm 1.06)$ \\
\hline DOC & $\mathrm{mg} / \mathrm{L}$ & $1.28( \pm 0.29)$ & $1.13( \pm 0.1)$ & $1.06( \pm 0.1)$ \\
\hline Suspended solids & & $5.23( \pm 0.73)$ & $5.8( \pm 1.7)$ & $3.3( \pm 0.96)$ \\
\hline Residual Al/Fe & $\mu \mathrm{g} / \mathrm{L}$ & $197( \pm 27)$ & $134( \pm 37)$ & $800( \pm 130)$ \\
\hline Particle count $(\leq 2 \mu \mathrm{m})$ & particles/mL & 79589 & 43931 & 68990 \\
\hline Particle count $(2-140 \mu \mathrm{m})$ & particles/mL & 16448 & 13134 & 14018 \\
\hline
\end{tabular}


Table 4. Parameters related to backwashing

\begin{tabular}{|c|c|c|c|c|}
\hline Hours of direct filtration (h) & $\begin{array}{c}\text { Sand/Everzit } \\
\\
9\end{array}$ & $\begin{array}{l}\text { Enviro/Filtralite } \\
20\end{array}$ & $\begin{array}{c}\text { AFM/Filtralite } \\
16\end{array}$ & $\begin{array}{c}\text { Filtec/Filtralite } \\
25\end{array}$ \\
\hline $\begin{array}{l}\text { Final effluent turbidity } \\
\text { (NTU) }\end{array}$ & 0.01 & 32.9 & 22.1 & .2 \\
\hline $\begin{array}{l}\text { Additional minutes of water } \\
\text { flow (min) }\end{array}$ & - & 5 & - & 15 \\
\hline $\begin{array}{l}\text { Final waste water turbidity } \\
\qquad \text { (NTU) }\end{array}$ & 7.63 & 12.1 & 2.83 & 6.83 \\
\hline Depth of intermixing of the & 10 & $6-7$ & $5-6$ & $8-9$ \\
\hline
\end{tabular}

